\title{
Fen Bilimleri ve Sınıf Öğretmeni Adaylarının Çevre Etiği Farkındalıklarının Farklı Değişkenlerce İncelenmesi a
}

\author{
Derya Sönmez ${ }^{b, c}$
}

\section{Özet}

Bu araştırmanın amacı Fen Bilimleri ve Sınıf Öğgretmeni adaylarının çevre etiği farkındalıklarının incelenmesidir. Araştırmada öğretmen adaylarının çevre etiği farkındalıkları cinsiyet, sınıf düzeyi ve bölüm değişkenine göre incelenmiştir. Araştırmanın örneklemini 2017-2018 akademik yılda bir devlet üniversitesinin Eğitim Fakültesinin Fen Bilgisi Öğretmenliği ve Sınıf Öğretmenliği bölümlerinin 1. ve 4. sınıflarında öğrenim gören 100 öğretmen adayı oluşturmaktadır. Araştırma, Fen Bilimleri ve Sınıf Öğretmeni adaylarının çevreye yönelik etik farkındalığını belirlemeyi amaçladığından dolayı nicel araştırma yöntemlerinden tarama modeli kullanılmıştır. Araştırmanın verileri Özer ve Keleş (2016) tarafından geliştirilen "Çevre Etiği Farkındalık Ölçeği" kullanılarak toplanmış ve veriler bilgisayar ortamında istatistiksel olarak analiz edilmiştir. Araştırma bulgularına göre Fen Bilimleri ve Sınıf Öğretmeni adaylarının çevre etiği farkındalıkları cinsiyete ve sınıf düzeyine göre anlamlı bir farklılık gösterdiği belirlenmiştir. Fen Bilimleri ve Sınıf Öğretmeni adaylarının çevre etiği farkındalıklarında öğrenim gördükleri bölümün anlamlı bir farklılık göstermediği bulunmuştur.

\section{Investigation of Environmental Ethics Awawreness of Science and Classroom Teacher Candidates by Different Variables}

Anahtar Kelimeler

Çevre Ĕ̆itimi

Çevre Etiği

Etik

\section{Makale Hakkında}

Geliş Tarihi: 27.03.2019

Kabul Tarihi: 19.12.2019

Doi: 10.18026/cbayarsos.545715

\begin{abstract}
The aim of this research is to examine the environmental ethics awareness of Science and Classroom Teacher candidates. Environmental ethics awareness of the pre-service teachers was examined according to gender, class level and department variable. The sample of the study consists of 100 candidate teachers studying in the 1st and 4th grades of the Science Education and Primary Education departments of the Faculty of Education of a public university in the 2017-2018 academic year. As the research aims to determine the ethical awareness of the candidates of science and classroom teacher in the environment, the screening model of quantitative research methods has been used. The data of the study were collected by using "Environmental Ethics Awareness Scale" developed by Özer and Keleş (2016) and the data were analyzed statistically in a computer environment. According to the findings of the research, it was determined that candidates of Science and Classroom Teachers had a significant difference according to gender and class level. It was found that the science and classroom teacher candidates did not show a significant difference in their environmental ethics education.
\end{abstract}

Keywords

Environmental Education

Environmental Ethics

Ethic

Doi: 10.18026/cbayarsos.545715

\footnotetext{
a Çalışma 19-22 Haziran 2019 tarihlerinde Ankara' da düzenlenen VIth International Eurasian Educational Research Congress'te "sözel sunum" olarak sunulmuştur. Bu çalışması ile yazar, Tübitak-Bideb 2224-b Yurtiçi Bilimsel Etkinliklere Katılım Desteği Programı (2019/2) tarafından desteklenmiştir. b İletişim Yazarı: deryasnmzim@hotmail.com

c Öğretmen, Milli Eğitim Bakanlığı/Kahramanmaraş-Türkiye. ORCID: 0000-0003-1265-9059.
} 


\section{Giriş}

İnsanoğlu, doğada varoluşundan bugüne değin doğadan yararlanmış, doğayı işlemiş, bilgi birikimine ve teknolojik gelişmelere paralel olarak doğaya egemen olmaya çalışmıştır. Bu çaba, başlangıçta uyum içinde olan doğa ile insan arasındaki dengeyi bozmuştur. Bilimin olanaklarına bürünen insan, kendini doğadan üstün görerek doğal kaynakları sınırsızca tüketmeye başlamıştır (Ürey, 2018).

Ekonomik büyüme adı altında çevreyi tahrip etmenin canlıların neslini sürdürebilmesini sağlamak hedefiyle uyuşmadığı ortadadır. İnsanların çevre ile uyum içerisinde yaşamlarını sürdürebilmesi ve çevreden ihtiyaçları doğrultusunda yararlanması yerine çevreyi kirletmeye, çevreyi sömürmeye, çevreyi yaşanmaz duruma getirmeye başlamaları ile beraber ilk ciddi küresel sorunlar ortaya çıkmıştır (Karaca, 2008). Çevre ile ilgili sorunlar bilim insanlarınca on yıllardan beri gündeme getirilmeye çalışılmış fakat insanlar, çevre ile ilgili sorunları, bu sorunların insan sağlığı üzerine olumsuz etkilerinin ortaya çıkmasıyla birlikte dikkate almaya başlamışlardır (Altunoğlu, 2010). Bu durumun etkisiyle birlikte insanlar çevre sorunlarına karşı daha duyarlı olmaya başlamışlardır (Des Jardins, 2006).

İnsan, diğer türlerden farklı olarak sorumluluk alanını sürekli genişleten ve kendi türdeşlerinin dışındaki varlıkları da ahlakın nesnesi olarak görüp kabul etme potansiyeline sahip bir varlıktır. Diğer varlıkları ahlaki nesne olarak kabul edecek olanlar ahlaki özne olan insanlardan başkası değildir. Ancak etik sorumluluğu üstlenme yetisinden yoksun olan bebekler, küçük çocuklar, zihinsel engelliler veya ciddi psikiyatrik hastalıklar yaşayan insanlar etik olarak yanlış kabul edilen bir edimde bulunduklarında onlar genellikle ayıplanmaz (Özer, 2017).

Etik, bir şeye ilişkin değer biçme etkinliğidir. Çevre sorunlarının insanlar tarafından iyice görünür duruma gelmesi ve insanların gündemine girmesi ile birlikte etik, insanın çevreye ilişkin edimlerini içine alarak yeni bir boyut kazanmıştır. Böylece insanın çevreye bakışına yön veren yeni bir etik dalı olarak çevre etiği doğmuştur (Özdemir, 2016).

Leopold'a göre çevre etiğinde değer kavramı oldukça önemli bir yere sahiptir. Ona göre insanları çevre ile ilişki kurmaya iten esas neden insanların çevre deneyimlerinden haz almaları ve insanların çevreyi kendilerini gerçekleştirme aracı olarak görmeleridir. Bundan dolayı çevrenin korunması insanların iyi yaşam idealine hizmet edecektir (Özer, 2017). Bu durumda, çevre etiği eğitimi süreçlerinin insan-çevre etkileşimi bağlamında önce değerler ve etik eğitimi olması gerekir. Çevreye yönelik her bir etik tercihin geri planında ona yön veren değer yargısı yer almaktadır. İnsanların çevreye karşı değer yargıları, araçsal (faydacı) ve içsel (özsel) olmak üzere iki ayrı uçta yer alır. Araçsal (faydacı) değer anlayışına göre insanın dışındaki diğer varlıklar insanlara sağladığı fayda ölçüsünde değerlidir. Buna karşıt olarak ekolojik dünya görüşünün temelini oluşturan içsel (özsel) değer anlayışına göre, bütün varlıklar yaratılışları nedeniyle değerlidir (Özdemir, 2016).

Çevre etiği, insanlar ile doğal çevreleri arasındaki ahlaki ilişkilerin sistemli olarak incelenmesidir. Çevre etiği, ahlak kuralarının insanların doğal dünya karşısındaki davranışlarını yönettiğini ve yönetmesi gerektiğini varsayar. Bir çevre etiği yaklaşımı bu kuralların neler olduğunu, insanların kimlere ve nelere karşı sorumlulukları bulunduğunu açıklamak ve bu sorumlulukların neden haklı olduğunu göstermek zorundadır (DesJardins, 2006). 
Çevre etiğini temel alan yaklaşımlar geçmişten günümüze kadar değişerek günümüze kadar gelmiştir. En eski çevre etiği yaklaşımı olan insan temelli etik yaklaşımından sonra canlı temelli etik ve çevre temelli etik yaklaşımlar da sırayla ortaya çıkmıştır (Özer, 2015). Çevre etiğini temel alan yaklaşımlar şöyle özetlenebilir:

İnsan Temelli (Antroposentrik) Çevre Etiği Yaklaşımı: Çevre etiğinin ilk yaklaşımı olan insan temelli çevre etiğine göre, sadece insan ahlaki bir değere ve öneme sahiptir (Des Jardins, 2006).

Canlı Temelli (Biyosentrik) Çevre Etiği Yaklaşımı: Canlıyı temel alan etik yaklaşıma göre bütün canlılar eşit hak ve sorumluluklara sahiptir. Canlı olmanın ahlaki bir değere sahip olmak için yeterli olduğunu savunmaktadır (Kılıç, 2008).

Çevre Temelli (Ekosentrik) Çevre Etiği Yaklaşımı: Çevreyi temel alan çevre etiği yaklaşımına göre, çevre sorunlarının ana nedeni antroposentrik (insan temelli) etiğin ortaya çıkardığ 1 bilimsel ve teknolojik gelişmenin doğa ve çevre üzerinde etki kurma çabasıdır. Böylece insanlar, bir yandan doğanın bozulmasına neden olmakta, diğer yandan ise doğadan gittikçe uzaklaşmaktadırlar (Özdemir, 2016).

Gelecek Temelli (Fütürist) Çevre Etiği Yaklaşımı: Geleceği temel alan çevre etiği yaklaşımına göre öncelikli olan gelecek kuşaklardır. Gelecek kuşaklar olarak sadece insanoğlu değil; bütün canlı ve cansız varlıklardır. Gelecek temelli çevre etiği yaklaşımının amacı, insanlar çevreden yararlanırken gelecek kuşakları düşündüğü takdirde şu anda var olan ve daha sonra ortaya çıkabilecek olan çevre sorunlarına karşı önlem sağlanabilecektir (Özer, 2015).

Leopold'a göre doğanın kaynaklarını kullanmak insanlara tanınmış bir ayrıcalıktır. Bu ayrıcalık insanlara doğal kaynakları gelecek kuşaklara aktarma sorumluluğu yüklemektedir. Etik değerlere sahip olan insanoğlunun doğayı bir kaynak olarak değil saygı duyulması gereken yaşayan bir varlık olarak görmesi gerekmektedir (Özer, 2017).

Küresel çevre sorunlarının giderek arttığı günümüzde, gelecekte devlet kurumlarında ve özel kurumlarda çalışacak ve çeşitli kurumlarda söz sahibi olacak öğretmen adaylarının çevre etiği farkındalıkları, günümüzde ve gelecekte oluşabilecek çevre sorunlarının önlenmesi amacıyla gelecek kuşaklar için önemli olacaktır (Sönmez, 2018). Çevre etiğini topluma uygulamanın en önemli yolu insanların çevre konusunda eğitilmesidir. Küçük yaşta verilen çevre etiği eğitimiyle çevre korumaya karşı farkındalık oluşturulabilir. Çevre etiği farkındalığının oluşturulabilmesi için sadece öğrencilere değil; öğrencileri eğiten öğretmenlere de büyük görevler düşmektedir. Bu nedenle öğretmenlerin yükseköğretimleri süresince aldıkları eğitimler sırasında başta çevre ve çevre ile ilgili dersler olmak üzere çevre etiği konusunda farkındalık düzeylerinin artırılması gereklidir. Çevre etiğinin farkında olan öğretmen, çevre etiğinin farkında olan öğrenciler yetiştirebilir (Özer, 2015).

Çevreye yönelik etik farkındalıkların oluşmasında küçük yaşların önemli olduğu düşünüldüğünde okullarımızda çevre ile ilgili ders ve konuları aktaran Fen Bilimleri ve Sınıf öğretmeni adaylarının kuşkusuz gelecek nesillerin çevre konusunda hassasiyetlerinin oluşmasında payının olacağı ortadadır. Çevre etiği boyutunda çevre bilgisine sahip olan Fen Bilimleri ve Sınıf Öğretmeni adaylarının gelecek kuşaklar için karar alma süreçlerinde çevre etiği farkındalığı ile kararlar vermelerinin günümüzde ve gelecekte doğal yaşamın korunması ve küresel çevre sorunlarının önlenmesinde önemli olacağ 1 söylenebilir. Bu çalışmada Fen Bilimleri ve Sınıf Öğretmeni adaylarının çevre etiği farkındalık düzeyleri ile ilgili elde edilecek veriler ışığında öğretmen yetiştirme öğretim programlarında yer alan Çevre Eğitimi, Çevre 
Bilimi gibi çevre ile ilgili derslerin çevre etiği boyutunda tekrar ele alınmasına katkı sağlayacağ1 düşünülmektedir.

Alanyazında ilgili çalışmalar incelendiğinde Fernandez Manzanal, Rodriguez Barreiro ve Carrasquer (2007) çalışmalarında üniversite öğrencilerinin çevreye yönelik tutumlarını; Karakaya (2009) çalışmasında Eğitim Fakültesi son sınıf öğrencilerinin çevreye yönelik bakış açılarını; Tuncay (2010) çalışmasında Fen Bilimleri Öğretmeni adaylarının yerel ve genel çevre sorunlarına karşı sergiledikleri etik uslamlama örüntülerini; Vlaardingerbroek ve Taylor (2010) çalışmasında Lübnan' daki ve Avustralya' daki öğretmen adayları ile branş gözetmeden çevre bilgi, tutum ve farkındalıklarını; Bülbül (2013) çalışmasında Fen Bilimleri Öğretmeni adaylarının sahip olduğu çevre etik algılarını; Özer (2015) çalışmasında Fen Bilimleri Öğretmeni adaylarının çevre etiği farkındalıklarını; Alpak (2016) çalışmasında Fen Bilimleri Öğretmeni adaylarının ekosentrik (çevre temelli) ve antroposentrik (insan temelli) tutumlarını; Bozdemir ve Faiz (2018) çalışmasında Sınıf, Sosyal Bilgiler ve Fen Bilimleri Öğretmeni adaylarının çevreye yönelik ekosentrik (çevre temelli), antroposentrik (insan temelli) ve antipatik yaklaşımlar açısından tutumlarını; Karakaya, Avgın ve Yılmaz (2018) çalışmalarında Fen Bilimleri Öğretmeni adaylarının çevreye yönelik etik tutumlarını; Gürbüzoğlu Yalmancı (2018) çalışmasında öğrencilerin biyoçeşitliliğin önemine yönelik çevre etiği anlayışlarını incelemişlerdir. Alanyazında yapılan çalışmalardan farklı olarak bu çalışmada, Fen Bilimleri ve Sınıf Öğretmeni adaylarının çevre etiği farkındalıkları farklı değişkenlere göre karşılaştırılmıştır.

Bu çalışmanın amacı Fen Bilimleri ve Sınıf Öğretmeni adaylarının çevre etiği farkındalıklarının cinsiyet, sınıf düzeyi ve bölüm değişkenine göre incelenmesidir. Bu amaca yönelik olarak aşağıdaki sorulara cevap aranmıştır:

Fen Bilimleri ve Sınıf Öğretmeni adaylarının, Çevre Etiği Farkındalık Ölçeğinden aldıkları ortalama puanları açışından;

a. Cinsiyete göre istatistiksel olarak anlamlı bir fark var mıdır?

b. Sınıf düzeyine göre istatistiksel olarak anlamlı bir fark var mıdır?

c. Öğrenim gördükleri bölümlere göre istatiksel olarak anlamlı bir fark var mıdır?

\section{Araştırmanın Sınırlılıkları}

Fen Bilimleri ve Sınıf Öğretmeni adaylarının çevre etiği farkındalıklarının farklı değişkenler tarafından incelenmesi amaçlanan bu çalışmada, veri toplama aracının alt boyutlarının göz ardı edilmesi araştırmanın sınırlılıkları arasında yer almaktadır.

\section{Yöntem}

\section{Araştırma Modeli}

Araştırma, Fen Bilimleri ve Sınıf Öğretmeni adaylarının çevreye yönelik etik farkındalığını belirlemeyi amaçladığından dolayı nicel araştırma yöntemlerinden tarama modeli kullanılmıştır. Tarama modeli, belirli bir grubun özelliklerini belirlemek amacıyla verilerin toplanmasını amaçlayan çalışmalardır. Bu araştırmada tarama araştırmalarından kesitsel tarama araştırması kullanılmıştır. Kesitsel araştırmalar genellikle birçok farklı özellikteki topluluğu kapsadığı araştırmalardır ve betimlenecek değişkenler bir defa ölçülür (Büyüköztürk, Kılıç Çakmak, Akgün, Karadeniz ve Demirel, 2014).

\section{Evren ve Örneklem}


Bir araştırma için evren, soruları cevaplamak için ihtiyaç duyulan verilerin elde edildiği canlı ya da cansız varlıklardan oluşan büyük gruptur (Büyüköztürk, Kılıç Çakmak, Akgün, Karadeniz ve Demirel, 2014).

Araştırmanın evrenini 2017-2018 akademik yılda bir devlet üniversitesinin Eğitim Fakültesinin Fen Bilgisi Öğretmenliği ve Sınıf Öğretmenliği bölümlerinde öğrenim gören öğretmen adayları oluşturmaktadır.

Örneklem evrenin tamamının incelenmesinin mümkün olmadığı durumlarda, araştırmadaki popülasyonu temsil etmesi amacıyla seçilen canlı veya cansız gruplardır (Büyüköztürk, Kılıç Çakmak, Akgün, Karadeniz ve Demirel, 2014).

Araştırmanın örneklemini 2017-2018 akademik yılda bir devlet üniversitesinin Eğitim Fakültesi'nin Fen Bilgisi Öğretmenliği ve Sınıf Öğretmenliği bölümlerinin 1. ve 4. sınıflarında öğrenim gören 100 öğretmen adayı oluşturmaktadır.

Araştırma örneklemini belirlemek amacıyla seçkisiz olmayan örnekleme yöntemlerinden biri olan uygun örnekleme yöntemi kullanılmıştır. Bu örnekleme yönteminde araştırmacı yakın ve erişilmesi kolay olan bir durumu seçmektedir. Bu da araştırmaya hız ve pratiklik kazandırır. Ayrıca maliyetin düşük olması da uygun örnekleme yönteminin tercih edilme nedenleri arasındadır (Yıldırım ve Şimşek, 2016).

\section{Veri Toplama Araçları}

Öğretmen adaylarının çevreye yönelik etik farkındalığının belirlenebilmesi için Özer ve Keleş (2016) tarafından fen bilimleri öğretmen adayları için geliştirilen 23 maddeden oluşan, 5'li likert tipli, dört alt boyuttan oluşan ve Cronbach Alpha güvenilirlik katsayısı 0,95 olan "Çevre Etiğ̣i Farkındalık Ölçeği (ÇEFÖ)" kullanılmıştır. Ölçeğin uygulama aşaması öncesinde öğretmen adayları, araştırma konusu (çevre etiği) ve ölçek hakkında bilgilendirilmiştir. Ölçeğin uygulama süresi yaklaşık 30 dakika sürmüştür.

Ölçeğin uygulama sonucunda elde edilen verilerden Cronbach alpha güvenirlik katsayısı hesaplanmış ve sonuçlar Tablo 1'de verilmiştir.

Tablo 1. ÇEFÖ Güvenirlik Analizi

\begin{tabular}{cc}
\hline Cronbach Alpha & Madde Sayısı \\
\hline 0,92 & 23 \\
\hline
\end{tabular}

Tablo 1 incelendiğinde ÇEFÖ güvenirlik analizinde ölçeğin Cronbach alpha güvenirlik kat sayısı 0,92 olduğu belirlenmiştir. Alpar (2016) güvenirlik katsayısının 0,80-1,00 arasında olması durumunda, ölçeğin güvenirliğinin yüksek olduğunu söylemektedir. Çalışmada kullanılan ölçeğin bu oranlara sahip olmasından dolayı yüksek güvenirliğe sahip olduğu söylenebilir.

\section{Verilerin Analizi}

$\mathrm{Bu}$ araştırmada elde edilen verilerin bilgisayar ortamında istatistiksel olarak analizleri yapılmıştır. Karşılaştırmalarda bağımsız örneklem t-testi kullanılmış olup ulaşılan sonuçlar \%95 güven aralığında değerlendirilmiştir. Değerlendirmede " $\mathrm{p}$ " anlamlılık düzeyi 0,05 olarak dikkate alınmıştır. 


\section{Bulgular}

Fen Bilimleri ve Sınıf Öğretmeni adaylarının, ÇEFÖ ortalama puanları açısından cinsiyete göre istatistiksel olarak anlamlı bir fark var mıdır? sorusuna cevap aranmıştır.

Bulguların analizinde bağımsız örneklem t-testi kullanılmıştır. Fen Bilimleri ve Sınıf Öğretmeni adaylarının, ÇEFÖ ortalama puanları açısından cinsiyete göre analizi Tablo 2' de gösterilmiştir.

Tablo 2. Öğretmen Adaylarının ÇEFÖ Ortalama Puanları Açısından Cinsiyete Göre Analizi

\begin{tabular}{lcccccc}
\hline Grup & $\mathbf{N}$ & $\overline{\boldsymbol{X}}$ & SS & Sd & $\mathbf{t}$ & $\mathbf{p}$ \\
\hline Kadın & 80 & 4,535 & 0,41 & 98 & 3,494 & 0,001 \\
Erkek & 20 & 4,108 & 0,72 & & & \\
\hline
\end{tabular}

Tablo 2 incelendiğinde öğretmen adaylarının ÇEFÖ aritmetik ortalama puanları açısından kadın öğretmen adaylarının $\left(X^{-}=4,535\right)$, erkek öğretmen adaylarına $\left(X^{-}=4,108\right)$ göre çevre etiği farkındalıklarının yüksek olduğu görülmektedir. Bağımsız örneklem t-testi analizi sonucunda ÇEFÖ ortalama puanları açısından cinsiyete göre istatistiksel olarak anlamlı bir farklılık olduğu belirlenmiştir. Ortalama puanlara bakıldığında, bu farklılığın kadın öğretmen adayları lehine olduğu tespit edilmiştir [t(98)=3,494; $\mathrm{p}<0,05]$.

Fen Bilimleri ve Sınıf Öğretmeni adaylarının, ÇEFÖ ortalama puanları açısından sınıf düzeyine göre istatistiksel olarak anlamlı bir fark var mıdır? sorusuna cevap aranmıştır.

Bulguların analizinde bağımsız örneklem t-testi kullanılmıştır. Fen Bilimleri ve Sınıf Öğretmeni adaylarının ÇEFÖ ortalama puanları açısından sınıf düzeyine göre analizi Tablo 3'de gösterilmiştir.

Tablo 3. Öğretmen Adaylarının ÇEFÖ Ortalama Puanları Açısından Sınıf Düzeyine Göre Analizi

\begin{tabular}{lllcccc}
\hline Grup & N & $\overline{\boldsymbol{X}}$ & SS & Sd & $\mathbf{t}$ & $\mathbf{p}$ \\
\hline 1. sinif & 50 & 4,279 & 0,58 & 98 & $-3,504$ & 0,001 \\
4. sinif & 50 & 4,621 & 0,36 & & & \\
\hline
\end{tabular}

Tablo 3 incelendiğinde öğretmen adaylarının ÇEFÖ aritmetik ortalama puanları açısından 4. sınıf öğretmen adaylarının ( $\left.X^{-}=4,621\right), 1$. sınıf öğretmen adaylarına $\left(X^{-}=4,279\right)$ göre çevre etiği farkındalıklarının yüksek olduğu görülmektedir. Bağımsız örneklem t-testi analizi sonucunda ÇEFÖ ortalama puanları açısından sınıf düzeyine göre istatistiksel olarak anlamlı bir farklılık olduğu belirlenmiştir. Ortalama puanlara bakıldığında, bu farklılığın 4. sınıf öğretmen adayları lehine olduğu tespit edilmiştir [t(98)= -3,504; $\mathrm{p}<0,05]$.

Fen Bilimleri ve Sınıf Öğretmeni adaylarının, ÇEFÖ ortalama puanları açısından öğrenim gördükleri bölümlere göre istatistiksel olarak anlamlı bir fark var mıdır? sorusuna cevap aranmıştır. 
Bulguların analizinde bağımsız örneklem t-testi kullanılmıştır. Fen Bilimleri ve Sınıf Öğretmeni adaylarının, ÇEFÖ ortalama puanları açısından öğrenim gördükleri bölümlere göre analizi Tablo 4'de gösterilmiştir.

Tablo 4. Öğretmen Adaylarının ÇEFÖ Ortalama Puanları Açısından Öğrenim Gördükleri Bölümlere Göre Analizi

\begin{tabular}{lcccccc}
\hline Grup & $\mathbf{N}$ & $\overline{\boldsymbol{X}}$ & SS & Sd & $\mathbf{t}$ & $\mathbf{p}$ \\
\hline Fen Bilgisi Öğretmenliği & 50 & 4,467 & 0,54 & 98 & 0,336 & 0,738 \\
Sinıf Öğretmenliği & 50 & 4,433 & 0,49 & & & \\
\hline
\end{tabular}

Tablo 4 incelendiğinde öğretmen adaylarının ÇEFÖ aritmetik ortalama puanları açısından Fen Bilgisi Öğretmenliği bölümü öğretmen adaylarının ( $\left.X^{-}=4,467\right)$, Sınıf Öğretmenliği bölümü öğretmen adaylarına ( $X^{-}=4,433$ ) göre çevre etiği farkındalıklarının yüksek olduğu görülmektedir. Bağımsız örneklem t-testi analizi sonucunda ÇEFÖ ortalama puanları açısından öğrenim gördükleri bölümlere göre istatistiksel olarak anlamlı bir farklılık olmadığı belirlenmiştir $[\mathrm{t}(98)=0,336 ; \mathrm{p}>0,05]$.

\section{Tartışma, Sonuç ve Öneriler}

Çevreye yönelik farkındalık hem kişiden kişiye hem de cinsiyet, ırk, toplumsal sınıf gibi etkenlere göre değişim göstermektedir (Garrard, 2016). Araştırmanın amacı doğrultusunda Fen Bilimleri ve Sınıf Öğretmeni adaylarının çevre etiği farkındalık düzeyleri belirlenerek, öğretmen adaylarının çevre etiği farkındalık düzeyleri cinsiyet, sınıf düzeyi, öğrenim görülen bölüm değişkenleri açısından incelenmiştir.

Araştırma bulgularına göre Fen Bilimleri ve Sınıf Öğretmeni adaylarının çevre etiği farkındalıklarında cinsiyete göre kadın öğretmen adayları lehine istatistiksel olarak anlamlı bir farklılık gösterdiği belirlenmiştir. Öğretmen adaylarının çevre etiği farkındalıklarının cinsiyete göre kadın öğretmen adayları lehine olmasında kadınların çevreye karşı daha duyarlı ve duygusal olmalarından kaynaklandığı söylenebilir. Alpak (2016) tarafından yapılan araştırmada, kadın Fen Bilimleri Öğretmeni adaylarının ekosentrik (çevre temelli) tutumlarının erkek Fen Bilimleri Öğretmeni adaylarına göre daha yüksek olduğu tespit edilmiştir. Araştırmacı bu bulguyu, kadın öğretmen adaylarının korumacılık ve sahiplenme içgüdülerinin erkek öğretmen adaylarına göre daha yüksek olması durumu ile ilişkilendirmiştir. Bozdemir ve Faiz (2018) farklı öğretmenlik programlarında öğrenim gören öğretmen adayları ile yaptıkları araştırma sonucunda, çevre etiğini oluşturan ekosentrik yaklaşıma yönelik farkındalıkların kadınların lehine olduğunu belirlemişlerdir. Keleş ve Özer (2016) yaptıkları araştırma sonucunda, cinsiyetin Fen Bilimleri Öğretmeni adaylarının çevre etiğine yönelik farkındalıklarını etkileyen bir faktör olduğunu belirtmişlerdir.

Araştırma bulgularına göre Fen Bilimleri ve Sınıf Öğretmeni adaylarının çevre etiği farkındalıklarında sınıf düzeyine göre 4. sınıf öğretmen adayları lehine istatistiksel olarak anlamlı bir farklılık gösterdiğ farkındalıklarında sınıf düzeyine göre 4. sınıf öğretmen adayları lehine olmasında yaş faktörünün etkisinin olduğu ve öğretmen adaylarının çevre ile ilgili akademik bilgi birikimlerinin 1. sınıf öğretmen adaylarına göre daha fazla olmasının etkisinin olduğu söylenebilir. Bozdemir ve Faiz (2018) çalışmalarında sınıf düzeyi açısından öğretmen 
adaylarının ekosentrik (çevre temelli) tutum puanları incelendiğinde 4. sınıf öğrencilerinin daha yüksek düzeyde ekosentrik (çevre temelli) tutuma sahip olduğu tespit edilmiştir. Araştırmacı bu durumu çevre konu/kavramların yer aldığı çevre eğitimi dersinin sınıf eğitiminde 4. sınıfta; günümüz dünya sorunları dersinin sosyal bilgiler eğitiminde 4. sınıfta; çevre bilimi dersinin fen bilgisi eğitiminde 3. sınıfta alındığından dolayı sınıf düzeyi arttıkça alınan derslerle ilişkilendirmiştir.

Araştırma bulgularına göre Fen Bilimleri ve Sınıf Öğretmeni adaylarının çevre etiği farkındalıklarında öğrenim gördükleri bölümün istatistiksel olarak anlamlı bir farklılık göstermediği bulunmuştur. Bu durumun nedeni olarak her iki bölümde Çevre Bilimi, Çevre Eğitimi gibi çevre ile ilgili derslerin veriliyor olması ve öğrencilerin çevre etiği konusuna eğitimci gözüyle ayn çerçeveden bakabilmeleri ile ilişkili olabileceği düşünülmektedir. Bozdemir ve Faiz (2018) tarafından yapılan çalışmada Sınıf Öğretmenliği, Fen Bilgisi Öğretmenliği ve Sosyal Bilgiler Öğretmenliği bölümü öğrencileri arasında çevre etiği tutum puanları arasında anlamlı bir farklılık bulunmamıştır. Karakaya ve Çobanoğlu (2012) tarafından yapılan çalışmada Bilgisayar ve Öğretim Teknolojileri Öğgretmenliği, Fen Bilgisi Öğretmenliği, İlköğretim Matematik Öğretmenliği, Sosyal Bilgiler Öğretmenliği, Okul Öncesi Öğretmenliği, Sınıf Öğretmenliği, Türkçe Öğretmenliği, İngilizce Öğretmenliği, Resim Öğretmenliği, Müzik Öğretmenliği, Rehberlik ve Psikolojik Danışmanlık bölümü öğrencilerinin çevre etiği yaklaşımlarının öğrenim gördükleri bölüme göre farklılık gösterdiği belirlenmiştir. Bu farklılı̆̆ın Okul Öncesi Öğretmenliği ve Resim Öğretmenliği bölümü arasında, Okul Öncesi Öğretmenliği bölümü öğrencileri lehine anlamlı bir farklılık olduğu tespit edilmiştir. Araştırmacı bu durumu Resim Öğretmenliği bölümü öğrencilerinin bireysel çalışmalarının etkisiyle birlikte ben merkezli durumlarla sıklıkla karşılaşmalarından kaynaklanmış olabileceğini belirtmiştir.

Sonuç olarak Fen Bilimleri ve Sınıf Öğretmeni adaylarının çevre etiği farkındalıklarında cinsiyet ve sınıf düzeyi değişkeninin etkisinin olduğu ancak öğrenim görülen bölüm değişkeninin etkisinin olmadığı belirlenmiştir. Erkek öğretmen adaylarının çevre ve çevre etiği ile ilgili etkinliklere aktif katılımları, çevre etiği konusunda farkındalıklarının artmasına katkı sağlayabilir. Eğitim Fakülteleri içerisinde yer alan bölümlerde çevre ile ilgili derslerin öğretim programlarına çevre ve çevre etiğini konu alan içeriklerin eklenmesi önerilebilir.

Araştırmanın sınırlılıkları doğrultusunda öğretmen adaylarının çevre etiği farkındalıkları, veri toplama aracının alt boyutları ile ele alınarak farkındalık düzeyleri açısını ortaya koyan yeni bir araştırma yapılabilir.

\section{Teşekkür ve Bilgilendirme}

Bu çalışma, 19-22 Haziran 2019 tarihlerinde Ankara'da düzenlenen VIth International Eurasian Educational Research Congress'te "sözel sunum" olarak sunulmuştur.

Bu çalışması ile yazar, Tübitak-Bideb 2224-b Yurtiçi Bilimsel Etkinliklere Katılım Desteği Programı (2019/2) tarafından desteklenmiştir.

Desteklerinden dolayı Türkiye Bilimsel ve Teknolojik Araştırma Kurumu-Bilim İnsanı Destekleme Daire Başkanlığı'na teşekkür ederim. 


\section{Kaynakça}

Alpak, G. (2016). Fen bilgisi öğretmen adaylarının çevreye yönelik etik yaklaşımları ile sürdürülebilir çevreye yönelik tutumlarının incelenmesi (Yüksek lisans tezi, Adnan Menderes Üniversitesi, Aydın). Erişim adresi: http://tez2.yok.gov.tr/

Alpar, R. (2016). Uygulamalı istatistik ve geçerlik-güvenirlik. Ankara: Detay Yayıncılık.

Altunoğlu, B. D. (2010). Ortä̈ğretim öğrencilerinin çevre risk algısı (Doktora tezi, Hacettepe Üniversitesi, Ankara). Erişim adresi: http://tez2.yok.gov.tr/

Bozdemir, H., \& Faize, M. (2018). Öğretmen adaylarının çevreye yönelik ekosentrik, antroposentrik ve antipatik tutumları. Sakarya University Journal of Education, 8(1), 61-75. DOI: 10.19126/suje.330546.

Bülbül, S. (2013). Fen bilgisi öğretmen adaylarının çevre etiği algıları üzerine bir araştırma (Yüksek lisans tezi, Gazi Üniversitesi, Ankara). Erişim adresi: http://tez2.yok.gov.tr/

Büyüköztürk, Ş., Kılıç Çakmak, E., Akgün, Ö. E., Karadeniz, Ş., \& Demirel, F. (2014). Bilimsel araştırma yöntemleri. Ankara: Pegem Akademi Yayınları.

Des Jardins, J. R. (2006). Çevre etiği-çevre felsefesine giriş. (çev.) Ruşen Keleş, Ankara: İmge Kitabevi Yayınları.

Fernandez Manzanal, R., Rodriguez Barreiro, L., \& Carrasquer, J. (2007). Evalution of enviromental attitudes: analysis and result of a scale applied to university students. Science Education, 91(6), 988-1009. DOI: 10.1002/sce.20218.

Garrard, G. (2016). Ekoeleştiri-ekoloji ve çevre üzerine kültürel tartışmalar. (çev.) Ertuğrul Genç, Ankara: Kolektif Kitap.

Gürbüzoğlu Yalmanc1, S. (2018). Kars il'inde öğrencilerin biyoçeşitliliğin önemine yönelik çevre etiği anlayışları. Kastamonu Eğitim Dergisi, 26(3), 907-912. DOI: 10.24106/kefdergi.415710.

Karaca, C. (2008). Çevre, insan ve etik çerçevesinde çevre sorunlarına ve çözümlerine yönelik yaklaşımlar. Çukurova Üniversitesi İktisadi ve İdari Bilimler Fakültesi Dergisi, 11(1), 19-33. Retrieved from https://dergipark.org.tr/tr/pub/cuiibfd/issue/4155/54500.

Karakaya, F., Avgın, S. S., \& Yılmaz, M. (2018). Fen bilgisi öğretmen adaylarının çevreye yönelik etik tutumlarının incelenmesi. Başkent University Journal of Education, 5(2), 225-232. Retrieved from http://buje.baskent.edu.tr/index.php/buje/article/view/167.

Karakaya, Ç., \& Çobanoğlu, E. O. (2012). İnsanı merkeze alan (antroposentrik) ve almayan (nonantroposentrik) yaklaşımlara göre eğitim fakültesi son sınıf öğrencilerinin çevreye yönelik bakış açıları. Türk Fen Ĕ̆itimi Dergisi, 9(3), 23-35.

Karakaya, Ç. (2009). Antroposentrik (insanı merkeze alan) ve nonantroposentrik (insanı merkeze almayan) yaklaşımlara göre eğitim fakültesi son sınıf öğrencilerinin çevreye yönelik bakış açıları (Yüksek lisans tezi, Ondokuz Mayıs Üniversitesi, Samsun). Erişim adresi: http://tez2.yok.gov.tr/

Kılıç, S. (2008). Çevre etiğ̈i ortaya çıkışı, gelişimi ve sonuçları. Ankara: Orion Kitabevi.

Özdemir, O. (2016). Ekolojik okuryazarlık ve çevre eğitimi. Ankara: Pegem Akademi Yayıncılık. 
Özer, M. (2017). Doğa etiğii. Ankara: İmge Kitabevi Yayınları.

Özer, N., \& Keleş, Ö. (2016). Çevre etiği farkındalık ölçeği geliştirme çalışması. Fen Bilimleri Öğretimi Dergisi, 4(1), 47-64.

Özer, N. (2015). Fen bilgisi öğretmen adaylarının çevre etiğine yönelik farkındalık düzeylerinin belirlenmesi (Yüksek lisans tezi, Aksaray Üniversitesi, Aksaray). Erişim adresi: http://tez2.yok.gov.tr/

Sönmez, D. (2018). Farklı fakültelerde öğrenim gören yükseköğretim öğrencilerinin çevre etiği farkındalık düzeylerinin incelenmesi (Yüksek lisans tezi, Kahramanmaraş Sütçü İmam Üniversitesi, Kahramanmaraş). Erişim adresi: http://tez2.yok.gov.tr/

Tuncay, B. (2010). Fen bilgisi öğretmen adaylarının yerel ve genel çevre sorunlarına karşı sergiledikleri etik uslamlama örüntüleri (Yüksek lisans tezi, Ortadoğu Teknik Üniversitesi, Ankara). Erişim adresi: http://tez2.yok.gov.tr/

Ürey, M. (2018). Çevre eğitimi. A. Tekbıyık \& G. Çakmakçı (Ed.), Fen bilimleri öğetimi ve stem etkinlikleri içinde (s.323-352). Ankara. Nobel Akademi Yayıncılık.

Vlaardigerbroek, B., \& Taylor, N. (2010). The environmental knowledge and attitudes of prospective teachers in lebanon: a comparative study. International Research in Geographical and Environmental Education, 16(2), 120-134.

Yıldırım, A., \& Şimşek, H. (2016). Sosyal bilimlerde nitel araştırma yöntemleri. Ankara: Seçkin Yayıncilik. 